\title{
Economía e intercambio desigual en una región transfronteriza: Arica, Chile-Tacna, Perú
}

\section{Economy and unequal exchange in a cross-border region: Arica, Chile-Tacna, Perú}

Recibido el 18 de agosto de 2017. Aceptado el 2 de abril de 2018. Publicado el 11 de mayo de 2018.

*Autor para correspondencia: Haroldo Dilla Alfonso, correo electrónico: hdillaalfonso@gmail.com

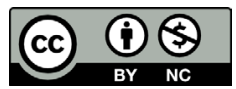

Esta obra está protegida bajo una Licencia Creative Commons Atribución-NoComercial 4.0 Internacional.
Haroldo Dilla Alfonso ${ }^{\text {a* }}$ (iD https:/lorcid.org/0000-0001-7744-8362 Camila Álvarez Torres ${ }^{b}$ (i) https://orcid.org/0000-0002-9045-0464

\footnotetext{
${ }^{a}$ Universidad Arturo Prat, Instituto de Estudios Internacionales, Santiago, Chile, correo electrónico: hdillaalfonso@gmail.com

${ }^{\mathrm{b}}$ Universidad Arturo Prat, Instituto de Estudios Internacionales, Iquique, Región de Tarapacá, Chile, correo electrónico: cami.alvarez.to@gmail.com, camalvarez@unap.cl
}

\section{Resumen}

El objetivo de este artículo es analizar los circuitos económicos que conforman el complejo urbano transfronterizo Arica-Tacna (Chile-Perú). Se apoya en una investigación cualitativa realizada en la zona que implicó entrevistas, observaciones y revisiones documentales. Sus conclusiones indican que se trata de una región transfronteriza muy intensa, pero acotada al ámbito local. Sus intercambios más significativos de mercancías ocurren en la informalidad y se canalizan a través de millones de cruces de personas en ambas direcciones. Se trata de un intercambio desigual favorable a la ciudad chilena.

Palabras clave: fronteras, región transfronteriza, ciudades, regiones, Chile, Perú.

\section{Abstract}

The aim of this paper is to analyze the economic circuits that make up the cross-border urban complex Arica-Tacna (Chile-Perú). It relies on a qualitative research carried out in the area involving interviews, observations and documentary reviews. Its findings indicate that it is a very intense cross-border region, but limited to local arrangements. Its most significant exchanges of goods occur in the informal economy and is channeled through million crossings of people in both directions. It's an unequal exchange favorable to the Chilean city.

Keywords: borders, cross-border region, cities, regions, Chile, Perú.

CÓMO CITAR: Dilla, H. y Álvarez, C. (2018). Economía e intercambio desigual en una región transfronteriza: Arica, Chile-Tacna, Perú [Economy and unequal exchange in a cross-border región:Arica, Chile-Tacna, Perú]. Estudios Fronterizos, 19, e009. doi:http: //doi. org/10.21670/ref.1809009 


\section{Introducción}

Las regiones transfronterizas (RTF) —que aquí definimos como articulaciones sistémicas espacio-temporales que comprenden territorios contiguos bajojurisdicciones nacionales diferentes - son partes frecuentes del paisaje planetario. En realidad, siempre existieron como espacios liminares, sea por comparticiones identitarias o por conveniencias de comunidades locales, toleradas en momentos en que las fronteras eran confines de patrias ordenadas por la geopolítica. Lo que les distingue en los tiempos actuales es, por un lado, su incremento numérico (en ocasiones bajo auspicio público), por otro la intensidad de sus intercambios que en ocasiones les vinculan de forma relevante a la economía global, y, finalmente, sus maduraciones como entidades territoriales organizadas en torno a ciudades.

Esta última cualidad ha inducido nuevos enfoques centrados en la naturaleza y perspectivas de las aglomeraciones urbanas. Sin espacio para seguir este debate - en particular en América Latina, un avance de lo cual puede encontrarse en Newman (2011), Herzog y Sohn (2014), Dilla (2015) y Tapia (2017) — valga mencionar que desde aquí se ha generado una extensa taxonomía para conceptualizar los fenómenos urbanos transfronterizos, sea desde la perspectiva funcional o desde sus impactos espaciales. Entre otros, se han acuñado términos como "sistemas metropolitanos binacionales" (Urdaneta, 2002); "ciudades transfronterizas" (Valero, 2006); "conurbaciones fronterizas", "región transnacional" y "corredor transnacional" (Peña, 2008); "sistemas urbanos", "conurbaciones" y "aglomeraciones binacionales" (Benedetti, 2014); y "complejos urbanos transfronterizos" (Dilla, 2015).

Este artículo pretende ser parte de esta discusión a partir del estudio del sistema transfronterizo que protagonizan dos ciudades sudamericanas - Arica en Chile y Tacna en Perú - distantes una de la otra por aproximadamente 60 kilómetros y que constituyen uno de los binomios urbanos de su tipo más intensos del hemisferio. Son dos ciudades medianas - para el año 2015 Arica reportaba 236000 habitantes (Biblioteca del Congreso Nacional de Chile, 2015) mientras que Tacna albergaba, según los datos de 2013, 317000 habitantes (INEI, s.f.) — y ambas asumían más de 90\% de la población de las regiones administrativas que encabezaban.

Nuestro punto de partida es la propuesta conceptual del complejo urbano transfronterizo (CUT) avanzada por Dilla (2015), y entendido como una situación funcional-espacial en que dos o más ciudades situadas sobre un borde internacional comparten un entorno, son económicamente interdependientes, sostienen contactos formales e informales y sus habitantes se perciben como mutuamente necesarios. Estas variables no definen una condición, sino informan de una gradación de situaciones fronterizas, que están determinadas por una relación sistémica multidimensional, y de la concurrencia en él de distintos intereses y grupos que inevitablemente incluyen la geopolítica, pero no se agotan en ella. Y en todos los casos, constituyen — citamos a Grimson (2000, p. 18)— "...sistemas relacionales basados en el conflicto".

Finalmente, una precisión metodológica: Este artículo se apoya en la investigación interdisciplinaria realizada en el marco del proyecto Conicyt-Fondecyt 1150812 sobre la regionalización transfronteriza en el norte de Chile. A partir de una revisión de la bibliografía existente —estudios académicos e informes técnicos- así como de la recopilación estadística pertinente, se realizó un trabajo de campo que contemplaba observaciones, entrevistas semiestructuradas, talleres y grupos focales. 
Con el objetivo de viabilizar el proceso investigativo, fueron construidos cuatro ámbitos de relacionamientos (público, transacciones económicas, cotidianeidad y medio ambiente) y cada uno de ellos segmentados en circuitos de relaciones considerados principales en el funcionamiento de la región. Finalmente, en cada circuito fueron identificados actores colectivos e individuales. Aunque la investigación se realizó primordialmente en Arica, algunos instrumentos fueron aplicados a actores en Tacna, en una suerte de reconstrucción transfronteriza de los procesos. La información que se brinda sobre las relaciones interurbanas proviene de las pesquisas de esta investigación, sus entrevistas y revisión de documentos operativos; no obstante, las ideas que aquí exponemos tienen — como el lector advertirá- un tono polémico, lo que persigue un objetivo vital para el trabajo académico: incentivar el debate como herramienta epistemológica, calistenia inseparable de aquello que Morin (2000, p. 59) llamaba "el derecho a la reflexión (en contraposición a) la confrontación ciega de los hechos o la verificación testaruda de hipótesis fútiles”.

\section{Tres problemas en un complejo urbano transfronterizo}

Este artículo se propone analizar tres cuestiones subyacentes e interrelacionadas en la constitución y funcionamiento del complejo urbano transfronterizo Arica-Tacna, particularmente desde su ámbito económico.

Una primera cuestión se refiere a la superposición de escalas. Todo cut se constituye desde una concurrencia de escalas (local, nacional, internacional, global, etc.). Pero no se trata de una superposición jerárquica sino de un traslapamiento complejo e irregular que provoca percepciones diferentes y actuaciones en consonancia de los actores involucrados. Bob Jessop (2001), en un artículo de tres lustros aún no superado, intentó dar cuenta de esa complejidad mediante un ejercicio taxonómico que agrupaba a las RTF según sus niveles de maduración y puntos de partida. Siguiendo su lógica, pudiéramos decir que el cut bajo estudio corresponde a una región larvada o autocontenida, donde la escala local organiza a las restantes.

Ello no hace alusión a grados de dinamismo — esta frontera es muy dinámica—sino a la manera cómo este dinamismo se realiza en relación con las escalas traslapadas. La concatenación de factores geopolíticos, históricos, geográficos y culturales determina que esta región no sea, como son otros CUT, un gozne de corredores extensos que penetran los espacios nacionales, involucran otras ciudades y van produciendo cadenas de valores que se relacionan con la economía global. No es el caso, para citar algunos ejemplos, del dúo Laredo-Nuevo Laredo, que no puede ser explicado sin entender las funciones de Austin, San Antonio y Monterrey; de la misma manera que la pareja Foz de Iguazú-Ciudad del Este es inseparable del rol de ciudades como Asunción y Curitiba; o que — a escala más discreta— la relación Dajabón-Ouanaminthe solo cobra sentido cuando asumimos las funciones dominantes de Santiago de los Caballeros y Cabo Haitiano.

No queremos decir que se trate de un conglomerado autárquico. Hay relaciones con otras ciudades (Iquique es un ejemplo) y también hay entradas y salidas respecto a la economía global, de lo cual, como veremos, dan cuenta dispositivos como el puerto de Arica y las zonas francas establecidas en la zona. Pero son vínculos poco relevantes para las economías nacionales, y aún menos para los espacios económicos globalizados del 
Pacífico Sur. Los numerosos flujos económicos entre Tacna y Arica se realizan localmente, y el ámbito económico transfronterizo se resuelve, en lo fundamental, en sí mismo. Y en consecuencia, la región transfronteriza Arica-Tacna aparece siempre como un territorio en formación, que ni siquiera logra madurar como un "modelo geoeconómico" crematístico e instrumental - que moviliza la frontera "como un beneficio diferencial dirigido a generar valor desde las interacciones transfronterizas” (Sohn, 2014, p. 598).

Muy ligado a lo anterior —el segundo problema- resulta la manera como se ordena la naturaleza multidimensional de este cUT. Un CUT, anotábamos antes, es el resultado de la interacción contradictoria de ámbitos diversos dados en la compartición ambiental, la economía, las relaciones consuetudinarias, la movilidad humana, la política formal o las representaciones discursivas. Cada uno de estos ámbitos tendrá, en cada caso, una manera de manifestación y un peso específico particular. Es indiscutible que en los momentos actuales en que la política formal nacionalista cede espacio -incluso reconociendo los amagos de teichopolítica descriptos por Rosiere (2011) - el factor crecientemente determinante de estas relaciones es la economía, cuyas transacciones ordenan el resto de las dimensiones.

Pero ni el ámbito económico, ni ningún otro, opera sobre el vacío estructural, sino que lo hace en medio de una constelación de interacciones que le condiciona. En nuestro estudio ocurre que los circuitos económicos dominantes se atienen a una serie de consideraciones geopolíticas (regularmente heredades de la Guerra del Pacífico), ${ }^{1}$ lo que origina una factura particular. Factores como el uso del puerto de Arica por Bolivia y Perú como resultado de los acuerdos de paz de 1904 y 1929, la prohibición peruana de inversión por extranjeros en un área de 50 kilómetros de la frontera, o el Plan de la Frontera Norte de Chile, son ejemplos. Pero sobre todo, lo que nos interesa destacar ahora, la actividad económica es viabilizada por una serie de relaciones consuetudinarias informales, con un peso muy limitado de lo que podemos llamar un ámbito económico formal. Este es un dato usual en las regiones transfronterizas en América Latina, pero lo que aquí constituye un signo resaltante - compartido por algunas otras experiencias sudamericanas- es que los circuitos económicos adquieren la forma de flujos de movilidad humana, dando lugar a una frontera muy transitada por personas, una de las más intensas del hemisferio en este sentido, más aún si contrastamos los datos de movilidad con los volúmenes poblacionales que la región contiene, y en consecuencia de acuerdo con Certeau (2008) estas prácticas sociales devienen "prácticas organizadoras" de los espacios urbanos y sus ámbitos de relacionamientos transfronterizos.

Esto plantea un reto heurístico a los estudios sobre el tema. Como veremos, no se trata solamente de la magnitud de los intercambios informales, sino de que estos ocurren en relaciones simbióticas con otras actividades con motivaciones no económicas, o que la informalidad entra y sale a conveniencia de los espacios propiamente formales. En consecuencia, no obstante la magnitud de estas relaciones económicas y de la interdependencia que generan, es poco probable identificar aquí una coherencia estructurada —en los términos discutidos por Harvey (2007) — de la economía política transfronteriza.

\footnotetext{
${ }^{1}$ Contienda bélica librada entre Chile por un lado y la alianza Perú-Bolivia por el otro entre 1879 y 1883. Su resultado fue la apropiación por parte de Chile del territorio boliviano de Antofagasta y peruanos de Tarapacá y Arica. El arreglo definitivo con Perú no se consiguió hasta 1929 en los términos que se explican más adelante.
} 
Finalmente, discutiremos cómo se expresa en términos sistémicos la conflictividad que antes aludíamos a partir del análisis del intercambio desigual, tal y como lo previó Emmanuel (1972), como transferencia neta de valores desde un segmento de la economía capitalista a otro.

La manera en que transcurre la relación Tacna-Arica — torrentes de personas que cruzan en ambas direcciones sin mayores contratiempos, que interactúan, edifican proyectos de vida o simplemente se divierten- ofrece una primera imagen de cordialidad y solidaridades; ello constituye un dato contrastante en una región marcada por el desasosiego geopolítico, lo que hace aflorar con frecuencia declaraciones públicas de los dirigentes locales aclarando que los temas de la relación interurbana no se apegan a los que cruzan el conflicto binacional. Estas avenidas auspiciosas de la relación transfronteriza tienen fuertes implicaciones para la convivencia comunitaria y para la forja posible de alguna forma de identidad mestiza, sentirse "de aquí y de allá a la vez" (Tarrius 2000, p. 41).

Hay poderosas razones históricas que condicionan este comportamiento. Las ciudades de Arica y Tacna constituyeron hasta mediados del siglo xIX un peculiar sistema urbano conformado por dos poblaciones ubicadas en pisos ecológicos diferentes de un mismo espacio nacional: Perú. Mientras que Arica giraba en torno a un puerto dedicado al trasiego mercantil del Alto Perú-Bolivia, Tacna era un típico centro de coordinación de actividades primarias, agropecuarias y mineras (Campus y Rosenblit, 2011). La Guerra del Pacífico trastocó esta relación y condujo finalmente a la separación política de ambas ciudades en 1929, a la luz del Tratado de Lima. Estas ciudades, por tanto, solo han vivido separadas jurisdiccionalmente desde 1929. Y la separación (conocida como la partija) nunca puso en duda los contactos personales y económicos, incluso en momentos geopolíticos muy ríspidos. Desde 2011, con la constitución de la Alianza del Pacífico, peruanos y chilenos no requieren pasaportes o permisos especiales para cruzar la frontera y pueden permanecer en el otro lado hasta por tres meses, aunque solo en condición turística.

Estas dos ciudades no solo son cercanas culturalmente, sino también en términos de bienestar. Tacna resulta uno de los departamentos menos pobres del Perú, con indicadores sociales que frecuentemente solo son superados por Lima, mientras que Arica debe conformarse con una posición media inferior en su contexto chileno. En otras palabras: Tacna es más próspera que la media del país que le contiene, mientras que Arica es más pobre respecto a la suya, lo cual expresa un tipo de relación usual en las fronteras. Esta situación y la política estatal peruana más interesada en las fronteras que la chilena, crean una imagen de equilibrio de bienestar social entre ambas ciudades. Algunos indicadores sociales tacneños igualan a los de Arica, y eventualmente pueden superarlos. Nada de ello es irrelevante, pero el área donde residen las diferencias más importantes, y que determinan la naturaleza de las relaciones entre ambas partes, ocurre en el campo de la economía y específicamente en materia de precios. El PIB per cápita chileno duplica al peruano, el salario mínimo es un tercio mayor y aunque la pobreza en cada parte es de difícil comparación por las diferencias metodológicas de los datos accesibles, todo indica que es superior en Tacna (Frigolett, 2013; Paredes, 2010), lo que se agudiza por el arribo a la ciudad de contingentes de migrantes peruanos y sudamericanos provenientes de las zonas aledañas, principalmente de las inmediaciones cordilleranas de Puno (Berganza, 2015).

Es desde esta asimetría que se construye y funciona el cut que hoy conocemos y que asombra a los espectadores por el paso incesante de personas en una u otra dirección. 
Se trata de un activo proceso de "....intercambios desiguales de valor económico entre diversos tipos de personas y regiones” (Kearney, 2008, p. 80) que, nuevamente contra las apariencias, beneficia a Arica en términos netos, la pieza dominante del binomio. Es, reiteramos la expresión de Grimson, un sistema relacional basado en el conflicto, donde este puede expresarse explícitamente como altercado (lo que ocurre con alguna frecuencia) pero también implícitamente, como dominación.

\section{El breve espacio de la formalidad}

El ámbito de la economía transfronteriza comporta varios circuitos que pueden reclamar la condición de la formalidad, es decir, circuitos cuyas actividades quedan registradas y satisfacen las obligaciones fiscales.

La principal motivación de estos circuitos formales es el uso del moderno puerto de Arica y de otros dispositivos comerciales enclavados en territorio chileno, como es la Zona Franca de Iquique (Zofri), ubicada a 300 kilómetros al sur de Arica. Cinco por ciento de las operaciones del puerto de Arica son mercancías peruanas (básicamente tacneñas) lo que implica unas 90 mil toneladas de carga. La Zofri, por su parte, ha devenido en una pieza clave del comercio de esta región. Aproximadamente la mitad de sus operaciones va dirigida a abastecer los mercados de Bolivia, Paraguay, Perú y Argentina. Entre 5\% y $8 \%$ de su carga se destina al mercado peruano, lo que constituye $90 \%$ de las importaciones que hace la Zona Franca de Tacna (Zofratacna) que a su vez es la suplidora de todo el comercio minorista en esta ciudad. Ello implicó en 2016 unos 195 millones de dólares (Zofri, 2016); de manera que, la mercancía que entra por Iquique y Arica suple el comercio peruano para ser adquirida primordialmente por consumidores chilenos que invaden los mercados de Tacna para disfrutar de sus bajos precios.

Las estadísticas oficiales chilenas respecto al tráfico de mercancías por el puesto fronterizo de Chacalluta ${ }^{2}$ (Aduanas de Chile, 2016), hablan de un flujo discreto. Las mercancías que salieron hacia Perú ascendieron para el año 2015 a 200186 toneladas; mientras que las entradas de mercancías llegaron a 230 038, y lo que pudiera ser más importante, la abrumadora mayoría de este movimiento se componía de mercancías en tránsito en virtud de los usos portuarios garantizados a Perú por el acuerdo de 1929. Es decir, se trataba de un flujo que estaba concentrado en Tacna (sin otros involucramientos importantes en el resto de Perú) y que limitaba lo que pudiéramos identificar como cadenas de valor a los usos del transporte ariqueño para movilizar las cargas.

Un segundo espacio de economía formal transfronteriza reside en el transporte que viabiliza los contactos. En el caso de las mercancías del puerto, este transporte es suplido por unos 120 camiones, todos chilenos, agrupados en cuatro asociaciones y compañías. En el caso del transporte de personas, dada la magnitud de este movimiento, se involucran varios centenares de trabajadores, sean choferes empleados o dueños de vehículos. En este caso, los transportistas chilenos y peruanos han acordado un sistema equitativo, en que al decir de un chofer, “...pelean todos días y se ponen de acuerdo tras cada pelea" (Ramiro, 2017).

${ }^{2}$ El puesto de control fronterizo chileno se denomina Chacalluta, mientras que el puesto peruano, ubicado a 500 metros de distancia, es conocido como Santa Rosa. Actualmente se ensaya un control integrado que mantiene el radio de espera entre una y dos horas, según el nivel de congestión. 
Además de los mencionados, otros circuitos transfronterizos formales se incubaban en áreas de producciones cooperadas, principalmente en la producción de aceitunas, un producto emblemático de Arica, cuya aceituna de Azapa (por el nombre del valle circum-urbano en que se produce) goza de alta estima y altos precios en el mercado capitalino. El Valle de Azapa, sin embargo, se encuentra en declive debido a su sobreexplotación, a la instalación de inversiones de transgénicos y a la competencia de productores emergentes en Tacna; y en consecuencia, los productores chilenos han comenzado a incursionar en Tacna donde consiguen un producto agrícola de igual calidad a menor precio, cuyo procesamiento industrial se culmina en Arica. Pero debido a la imposibilidad de invertir directamente en Perú, deben realizar sus operaciones en un marco de oscuridades informales que saben usar convenientemente para el incremento de ganancias y la evasión fiscal. Un argumento reiterado entre los empresarios tacneños legalmente establecidos fue la necesidad de establecer reglas claras en asuntos como los sistemas de inspección aduanera, el cambio de moneda y los deberes fiscales en aras de un cálculo de previsibilidad que consideraban vital para lo que una dirigente de una asociación de productores de aceitunas llamaba "sanidad del mercado".

\section{Buscando la sobrevivencia}

Si la relación Tacna-Arica se limitara a estos contactos económicos formales, habría que pedir muchas disculpas al hablar de un complejo urbano transfronterizo. Como anotábamos antes, el dato empírico distintivo de la relación interurbana - y que nos permite resaltar la relevancia de este CUT- está dado por la movilidad de personas en una u otra dirección y que a los efectos de este artículo pueden ser consideradas mayoritariamente como vendedoras y compradoras de mercancías, sea de fuerza de trabajo, bienes o servicios. Estas personas provienen de una veintena de nacionalidades, pero más de $95 \%$ de ellas son chilenas y peruanas, casi a partes iguales. Según las estadísticas oficiales chilenas (Aduanas de Chile, 2016) en este año se realizaron hacia Perú 3120686 cruces y hacia Chile 3175 477, para totalizar más de 6.3 millones de cruces. Estadísticas no confirmadas hablan de siete millones de cruces en el 2017. Esto sitúa a este binomio urbano en una posición cimera en América Latina, junto a manchas urbanas como son Ciudad del Este-Foz de Iguazú-Puerto Iguazú o el binomio Cúcuta-Ureña-San Cristóbal.

Un primer componente de esta intensa movilidad poblacional proviene del tránsito de miles de trabajadores peruanos hacia diversas actividades productivas y de servicios, y en particular, hacia la agricultura, que tiene lugar en los valles circum-urbanos de Lluta y Azapa. Por razones antes explicadas, estos valles agrícolas constituyen mercados segmentados en el sentido explicado por Piore (1971) y cuyas producciones solo pueden resultar competitivas cuando entran en contacto con factores abaratadores de precios, como es la fuerza de trabajo peruana. No olvidemos que estos braceros no gozan usualmente de estatus migratorios adecuados para trabajar — lo que les somete a una situación de vulnerabilidad legal- y que no constituyen migrantes en términos técnicos, sino fuerza de trabajo estacional lo que implica una redituable separación de los lugares de la producción y la reproducción de la mano de obra en beneficio de las tasas de acumulación (Kearney, 2003). Por otra parte, estos braceros llenan el vacío 
que dejan los trabajadores ariqueños que se emplean en las explotaciones mineras de las regiones de Tarapacá y Antofagasta, con salarios significativamente superiores y sus consiguientes impactos positivos sobre las economías familiares.

Los empleadores chilenos entrevistados mostraban un nivel alto de aceptación de los trabajadores peruanos, a quienes consideraban una mano de obra idónea. "Nunca falta gente”, decía un empresario agrícola mediano:

Ahora que hay esfuerzo lo hay... trabajar de sol a sol, no gastar y luego comprarse algo propio... el peruano es desconfiado y callado con otros peruanos, pero buen trabajador, hace lo que debe hacer, reclama poco, nunca pide permiso, a menos que sea emergencia, puede llegar encañado (ebrio) pero te trabaja igual, entonces no es mi problema, pero pagamos bien, son como 20.000 pesos al día, si hacen más sacos, hay unas monedas extras, es bastante en la semana cuanto y te ahorras la casa, no es malo el trato, que van a hacer, si allá están a penas y acá hay algún futuro (Manuel, 2016).

Los trabajadores peruanos en Arica se insertan en la parte inferior de la pirámide social: como trabajadores no calificados, sin estatus legal para trabajar, usualmente desprovistos de contratos y con salarios bajos. La frecuente referencia encontrada en las entrevistas acerca de ellos como "introvertidos", "nada quejosos" y "dispuestos para lo que haga falta" encierra un drama de una población obligada a hacer lo que los trabajadores chilenos no están dispuestos a hacer. La propia cifra que menciona el empresario -20 000 pesos, al cambio del momento unos 30 dólares_- es equivalente a 3.5 salarios mínimos peruanos. Es decir, sumas relativamente altas, pero que se obtienen trabajando largas jornadas de hasta 12 horas diarias, con alojamientos muy precarios, en las mismas fincas (en ocasiones entre los mismos surcos) o en asentamientos irregulares particularmente deprimidos, separados de la familia y expuestos a discriminaciones y abusos. Cargan consigo la doble subordinación remarcada por Fraser (2006) del estatus en el plano cultural y de la clase desde las entrañas de la economía.

Otro flujo relevante de trabajadores se compone de personas - principalmente mujeres- de ambas nacionalidades que se involucran en diferentes formas del llamado "comercio hormiga", entendido como "redes sociales que operan de una manera horizontal descentralizada (...) formadas por grupos domésticos que buscan nichos económicos donde poder explorar las actividades comerciales que son consideradas ilícitas" (Lins, 2015, p. 415). Se trata, anota Gauthier (2015, p. 256), de un tráfico comercial caracterizado "...tanto por la alta frecuencia del desplazamiento transfronterizo como por el reducido volumen de productos transportados por viaje".

Un primer grupo lo constituyen personas que transportan a Arica pequeñas cantidades de mercancías adquiridas en Tacna, y en cantidades sujetas a las normas aduanales. Lo pueden hacer a cuenta propia o por encargo (comisionistas), para suplir familias contratistas o pequeños comercios, en detrimento del fisco pero en beneficio de los consumidores. Es el caso de una mujer entrevistada que viajaba semanalmente para abastecer una pequeña tienda propia de licores, golosinas y cigarrillos. Lo hacía junto a un grupo de amigas que tenían finalidades similares, lo que le daba un toque social al viaje y les permitía un "acomodo de carga" para evitar decomisos en aduanas. Aunque compraba algunos productos en Chile para justificar las existencias con boletas formales, en realidad su mayor oferta provenía de los productos que traía en sus viajes, los que vendía más baratos, aunque con ganancias considerables. Debe hacerse notar 
que cuando este trasiego se hace por comisionistas, estas mujeres pueden cruzar la frontera hasta tres veces en el día. ${ }^{3}$

Pero la razón principal de este flujo es, en dirección contraria, el comercio de ropas y tejidos de segunda mano que se mueve desde Arica hacia Tacna. Este tráfico muestra una suerte de especialización en dos sentidos. Por un lado, son actividades feminizadas; aunque en determinados momentos de estos procesos es posible encontrar hombres - por ejemplo en el tráfico evasivo de las mercancías por pasos fronterizos no habilitados- son circuitos copados por mujeres, incluso en aquellos momentos en que las actividades se concentran en términos de propiedad, por otro lado, son circuitos fuertemente etnizados, en nuestro caso poblados y controlados por personas peruanas y bolivianas, frecuentemente aymarás. Una y otra condición implica efectos positivos en sectores vulnerables socialmente. Por ejemplo, erosiona los aspectos más gravosos de la dominación patriarcal, al contribuir a la independencia económica y a la autoestima de muchas mujeres. También ha resultado un mecanismo importante de incorporación de mujeres migrantes en Arica. Pero no es posible soslayar que por estas mismas razones, son actividades relegadas simbólicamente en sociedades patriarcales y nacionalistas, como las que aquí nos ocupan.

Este comercio no confiere prestigio ni ahorros. Al decir de una mujer peruana de 38 años que hace su vida traficando paquetes entre nuestras ciudades, "...te miran mal y te permite darte vuelta en lo que es sobrevivir, no más" (María, 2016). Otra, chilena de 44 años, que proclama su buena fortuna, recuerda algo que le dijeron cuando empezaba: "...no le va a faltar nada en su casa pero usted no se va a hacer rica vendiendo ropa usada acá” (Rosa, 2016).

Este comercio se monta sobre una situación paradójica: está prohibido en Perú pero es permitido por el gobierno regional de Tacna. Por consiguiente, el lugar de aprovisionamiento es Arica, donde la ropa de segunda mano entra por el puerto, aprovechando las franquicias de la Zona Franca de Iquique. En Arica este comercio se organiza escalonadamente desde una docena de grandes almacenes hasta una miríada de pequeños puntos de distribución, casi siempre ubicados en torno a la terminal terrestre de buses y taxis que conecta a Arica con Tacna. El trabajo de acarreo de esta ropa está a cargo de diferentes personajes — cachineras, comisionistas, pamperos, y unos pocos empresarios que controlan la circulación en Tacna- todo lo cual ha sido descripto por Peña (2009) y por Guizardi Valdebenito, López y Nazal (2015). Gráficamente, los flujos semejan una suerte de huso que se concentra en sus extremos y se capilariza en su centro, donde centenares de personas peruanas se despliegan en los momentos más riesgosos y peligrosos del tráfico.

Debe hacerse notar que también en Arica existe un mercado de ropas usadas en buena medida copado por mujeres aymarás y quechuas. Aquí compartían mostradores con mujeres chilenas, que frecuentemente alegaban discriminaciones por parte de las mujeres peruanas y bolivianas. Pero también era distinguible un grupo de vendedoras chilenas de pocas mercancías, precios mayores y clientes selectos que —en otra vuelta

\footnotetext{
${ }^{3}$ Aduana de Chile en este punto establece — según las entrevistas efectuadas - un máximo de valores libres de 500 dólares, pero también existen límites de cantidad de productos. Dado que es imposible calcular los precios, la observación se hace sobre el número de productos. Ello establece, por ejemplo, tres litros de aceite, dos botellas de alcohol (destilados o cervezas), un $\mathrm{kg}$ de azúcar, dos $\mathrm{kg}$ de arroz, doce botellas de bebidas no alcohólicas y dos cartones de cigarros. Por esta vía puede imaginarse la magnitud de un tráfico que implica un promedio de unos 10000 cruces diarios en cada dirección.
} 
singular de la relación transfronteriza- compraban las ropas usadas en Tacna, para luego revenderlas en Arica, en la consideración del buen trato que recibían en Tacna y de que las mercancías, ya pasado el tamiz de la selección, era de calidad superior. Para ello realizaban viajes personales o usaban a terceras personas, regularmente mujeres peruanas. Una comerciante chilena de 34 años que se enorgullece de tener entre sus clientes a muchos universitarios que ya no consideran lesivo a su status vestir con prendas de segunda mano, describía así su "plan de negocios":

También he comprado ropa de marca en Tacna. Primero que todo, yo iba a Tacna, iba y compraba por dos, tres prendas, cuatro prendas y con el tiempo me di cuenta que había gente de Tacna que pasa cosas y se les paga a ellos una cantidad de dinero, por prenda generalmente, las poleras de marca, las casacas de marca, cosas super buenas [...] El método de ellas es que uno le pasa la cantidad, por ejemplo 10 prendas. Le puede pagar la mitad o se les paga acá en Arica, cuando llegan. Estas pasantes trabajan todo el día, pero solo después de las 8 de la noche llegan a pasar las cosas. Ellas juntan de muchas gentes y las marcan, les ponen el nombre de uno... y después cuando ellas llegan acá en el terminal internacional le entregan las prendas y uno termina de pagarle lo que le piden (Teresa, 2016).

En otras palabras, la ropa usada entra por el puerto de Arica y es transportada por mujeres peruanas hacia Tacna, donde mujeres chilenas la encargan para ser devueltas y vendidas en Arica, posiblemente por las mismas mujeres que las llevaron en dirección opuesta.

Por último, aunque este tipo de comercio hormiga hacia Arica lo practican personas de ambas nacionalidades, no lo hacen con igual suerte. Aquí la frontera desempeña su rol clasificador, "como filtros selectivos que permiten pasar ciertas cosas y no otras" (Kearney, 2008, p. 97). Una comerciante chilena lo dijo casi en susurro, pues "suena feo", "pero en el control de Chile, cuando te ven cara de chilena no te paran, tu puedes pasar, yo una vez pase 5 botellas sola y me dejaron pasar. Y atrás mío venía una paisanita que venía con 7 poleras y la hicieron parar y le quitaron las poleras" (Rosa, 2016). Dice una joven comerciante que estudia sicología:

Me acuerdo una vez que vi a una señora que pasó una bolsa matutera llena de estas cosas como quinoa, y si, le hicieron caleta de drama pero igual es como bien discriminatoria la weá porque es como... ella tenía pinta de chola, entonces les hacían problema. Pero nosotros igual, hemos pasado bolsas matuteras y nada (Teresa, 2016).

\section{Comprando barato en la playa de ocio}

Otro flujo identificable — sin lugar a dudas el más fotogénico — corresponde a los chilenos que visitan Tacna con fines de consumo, sea de bienes o servicios. Según los datos obtenidos de la Dirección General de Migración y Naturalización en Tacna, en el año 2015 cruzaron a esta ciudad por Chacalluta-Santa Rosa un total de 1684 421 personas extranjeras, más de $90 \%$ eran chilenas, el doble de las que lo hicieron en 2009. De ellas, $11 \%$ eran propiamente turistas que pernoctaban en la ciudad. El resto eran personas que solo pasaban un día y que son registradas como visitantes. 
Los primeros gastaban 64 dólares diarios, y los segundos 56, es decir, una diferencia modesta. En total dejaban a la ciudad unos 100 millones de dólares anuales, algo menos que lo que dejaba el turismo nacional que movilizaba una cantidad similar de personas peruanas. En 2018, un periódico local — posiblemente con una nota de exageración- reportaba que en solo un fin de semana en época de vacaciones habían pasado a Tacna 46000 chilenos y habían gastado 4 millones de dólares, en lo que consideraba un récord histórico (Narváez, 2018).

Una encuesta desarrollada por Zofratacna (2016) a 407 chilenos visitantes (es decir, que no pernoctan en la ciudad) mostró datos ilustrativos. De los visitantes, $35 \%$ tenían como finalidad principal la recreación, básicamente gastronómica; 34\% reportaba motivaciones de cuidados de salud y $22 \%$ exclusivamente a hacer compras. Finalmente, casi todos realizaban compras, por lo que mercados y centros comerciales eran los lugares en que gastaban más tiempo para $79 \%$ de los entrevistados. Compraban una infinidad de productos, pero más usualmente ropas (67\%), bebidas alcohólicas y cigarrillos (19\%) y zapatos (11\%). La encuesta mostraba un uso diferenciado de Tacna según los recursos económicos: las familias más pobres la usaban estrictamente para hacer compras sobre la base de precios convenientes, mientras que los grupos con más ingresos enfatizaban el lado lúdico y la variedad de ofertas. Es interesante que $95 \%$ de los entrevistados mostraban satisfacción por la estancia y aseguraba regresar.

El consumo de los servicios de salud de Tacna resulta un mecanismo eficaz que usan los ariqueños para evadir los altos costos y las demoras que caracterizan al servicio en su ciudad. En primer lugar, se expresa en la alta concurrencia al Hospital de la Solidaridad de Tacna, una modalidad de provisión de servicios médicos eficiente y mediante pagos discretos. En 2016, según la estadística interna de la institución, se recibió la visita de 59.766 personas chilenas, $71 \%$ de Arica, lo que significaba $45 \%$ de la totalidad de sus consultas. Estos servicios médicos se completan con la existencia de una red de farmacias, ópticas, gabinetes odontológicos, y otros establecimientos accesorios a todo lo largo de aquellos lugares por donde se mueven los visitantes chilenos. Estos establecimientos están adaptados para un servicio rápido de precios muy moderados para los ingresos chilenos. De manera que, para poner un ejemplo, unos lentes de aumento pueden ser conseguidos en unas tres horas y a un tercio del precio de Arica, donde la entrega puede demorar hasta dos semanas.

Al mismo tiempo, Tacna es usada por los ariqueños como plaza comercial, debido a sus precios bajos. Como antes decíamos, una parte de este consumo satisface el comercio hormiga, mientras otra va dirigido a compensar las necesidades domésticas. Las entrevistas efectuadas en torno al tema, principalmente realizada a mujeres, indican la frecuente recurrencia a una serie de productos de uso cotidiano que pueden ser preferidos por el apego a marcas o por sus precios económicos, como son azúcar, papel sanitario, detergente, atún enlatado, café, leche en polvo, bebidas alcohólicas y cigarrillos. Este consumo se realizaba mediante prácticas diferentes. Una mujer entrevistada, por ejemplo, realizaba unos siete viajes al año para efectuar compras de estos productos para consumo estrictamente doméstico, lo que aprovechaba para gastar parte del tiempo en actividades lúdicas. El viaje con la familia tenía la ventaja adicional de incrementar los volúmenes de mercancías que podía introducir al país según las normas de aduanas. Otra era una estudiante de la universidad local, que confesaba que la única manera de hacer rendir su mesada era comprando en Tacna, por lo menos dos veces al mes, viajes que eventualmente aprovechaba para comprar algunas cosas que revendía a sus colegas. 
Según los cálculos realizados a partir de entrevistas a seis personas que realizaban compras para consumo familiar en Tacna, estas implicaban ahorros de entre 50000 y 60000 pesos chilenos (75-90 dólares estadounidenses) mensuales por familia. ${ }^{4}$ En un caso en que la mujer entrevistada compraba medicinas en Tacna para un familiar con una convalecencia crónica, el ahorro mensual se elevaba a 120 000-150 000 pesos (185-230 USD aprox.), todo lo cual resulta muy relevante en un lugar donde los salarios medios no rebasan los 400000 pesos (587 USD) y los ingresos familiares promedian 820000 pesos (1 204 USD aprox.) mensuales (INE, 2016).

Una mujer, profesional —y con no más de 30 años—fijaba su atención en consumos selectivos tales como café, condimentos, cigarrillos y licores. Viaja a Tacna cada dos meses con su pareja, pero no lo hace con un solo propósito:

Lo primero siempre es la recreación y salir y comer y tomar, despejarse y estar desconectada de los celulares... Entonces son como uno o dos días donde uno puede relajarse y uno aprovecha de comprar, porque es como idiota ir a Tacna y no comprar (Huris, 2016).

La joven profesional toma a Tacna por su lado glamoroso: su conversión en una suerte de playa de ocio para los chilenos. En realidad la ciudad ha logrado dotarse de una red de restaurantes económicos y de alta calidad, hoteles de varias gradaciones y casinos que fascinan a los visitantes ariqueños. "En los casinos, comentaba un joven chofer de 33 años que visita Tacna casi todos los fines de semana, te dan el trago gratis mientras juegas, pero en Chile hay que pagarlo" (Miguel, 2017). Estos establecimientos se ubican generalmente en un circuito de tránsito de los chilenos (Avenidas Bolognesi, San Martín y Coronel Mendoza), alejándose del centro según se incrementa el tono pecaminoso del consumo.

En las afueras, en la zona de Alto Chorrillo, funcionan los burdeles especializados para los chilenos (Las Cucardas, El Venus, Las Pasiones), donde los precios por una tanda de sexo son $25 \%$ del servicio en un prostíbulo ariqueño. La prensa local ha dado cuenta de este fenómeno, pero nada más ilustrativo que una página web con el pomposo nombre de "Manual completo para ir y regresar de Las Cucardas TacnaPerú", de donde citamos textualmente un fragmento respetando la ortografía original: "Al llegar a las cucardas vas a tener que cancelar una entrada de 2 soles (algo así como $\$ 360$ pesos chilenos) luego de eso a disfrutar se a dicho! [sic]".

\section{A modo de conclusiones: Intercambio desigual e identidades mestizas}

Un lugar común de la doxa localista en ambas ciudades es que Tacna ha sido exitosa en su relación con Arica y ha devenido en la principal beneficiaria de la relación. Es una convicción particularmente arraigada en Arica donde la élite local sufre una suerte de "pesimismo colectivo" añorante de un pasado que no retorna y recelosa de dos vecinas más audaces: Tacna e Iquique (Universidad de Tarapacá, Red de Desarrollo Económico Territorial y Empleo para América Latina y el Caribe, 2008). Pero nadie lo

\footnotetext{
${ }^{4}$ La conversión en dólares se realizó con la información proporcionada por el Servicio de Impuestos Internos de Chile, utilizando el promedio del mes de junio del año 2016.
} 
expresó mejor que un ariqueño jubilado que ha llegado a su octava década de vida y asegura "haber visto todo":

Acá Tacna se beneficia más con nosotros, porque todos se van para allá, en vez de dejar acá... como le digo... en vez de dejar el beneficio acá, van al otro lado, como a depositar, y van en cantidad y bueno una con otra, porque también en años pasados también nos tocó a nosotros, que todos se venían para acá, en los años 60 por ahí... En ese tiempo Tacna era menos que Arica podemos decir, en cuanto a su desarrollo, a su cultura misma... pero ahora como que nos están ganando, ahora, allá nos ganaron en cuanto al adelanto de sus construcciones... de su crecimiento. Entonces ahora se dio vuelta todo eso (Entrevistado, 2017).

La "vuelta de todo eso" que argumentaba el anciano es parte de la vida en una frontera, y también afecta la percepción de las cosas. Tacna, sin lugar a dudas, se ha dotado de una imagen más fotogénica que Arica pero ello no implica mayor desarrollo, ni captación de cuotas mayores del plusproducto regional: es la diferencia entre la pasarela y la acumulación.

Nadie puede negar los avances de Tacna en esta relación. En algo más de medio siglo ha multiplicado su población treinta veces hasta alcanzar una cifra superior en más de un tercio de la población de Arica. Sus indicadores económicos y de bienestar social - como vimos antes - también han mejorado y hoy se ubica como una de las ciudades menos pobres del Perú. Todo ello ha estado ligado a políticas nacionales. Perú tiene una política más proactiva y desarrollista hacia sus fronteras que Chile, en lo que influye tanto su adherencia al pacto regional de la Comunidad Andina como la acogida calurosa que los peruanos dieron a la ciudad retornada tras décadas de secuestro chileno. Pero si estas políticas nacionales han sido tan exitosas se debe a la existencia de un entramado empresarial y político regional capaz de aprovechar las oportunidades de la frontera.

El punto neurálgico de esta dinámica ha sido la Zona Franca de Tacna. Paulatinamente moldeada desde 1989 y finalmente decretada en 2002, la Zofractana ha sido particularmente exitosa en el control del comercio regional y su organización desde una perspectiva transfronteriza. Debido a su relevancia económica, este complejo económico ha sido un partícipe directo de varios organismos colegiados y en la formulación de políticas públicas locales, lo que ha creado en Tacna un sector empresarial con un discurso y una visión de futuro más sofisticados que sus homólogos ariqueños.

No puede negarse el impacto positivo que esto tiene en la ciudad de Tacna. Pero cualquier acercamiento racional a esta relación sugiere de inmediato un callejón sin salida: el atractivo definitivo que tiene Tacna sobre Arica no es, en lo fundamental, la calidad de sus servicios, sino sus precios. Estos precios pueden conseguirse por diferentes estrategias comerciales — por ejemplo mediante la economía de escalaque los empresarios de Zofratacna conocen y saben usar, pero el factor decisivo es indudablemente el desarrollo desigual. En consecuencia, en el marco de una relación sistémica muy contradictoria, la ciudad tiene a su pobreza relativa como su carta principal. Y Arica, aun cuando efectivamente desaprovecha oportunidades debido a la incapacidad de empresarios y políticos, saca las mejores partidas de esa pobreza. Miles de braceros hacen producir en condiciones de alta rentabilidad las franjas agrícolas de Azapa y Lluta, llenando el vacío que dejan miles de braceros ariqueños que se emplean 
en las zonas mineras mejor pagadas de Tarapacá, Antofagasta y Copiapó. Sus economías familiares se benefician de los bajos precios de los servicios y los bienes en Tacna, sea buscando salud, divirtiéndose o llenando los anaqueles de las despensas. El uso del puerto por las empresas tacneñas no solo contribuye a su funcionamiento, sino que también genera actividades de transporte y acarreo que es realizado por compañías chilenas.

Tacna, por su parte, debe asumir una serie de costos invisibles derivados de su relación con Arica. En otras partes de este artículo hemos comentado algunos de estos costos, como la recepción de flujos de personas pobres - peruanos y sudamericanosatraídos por las oportunidades, siempre insuficientes, de la ciudad. No menos significativa es la expansión de la prostitución, con sus implicaciones en términos de salud; no es casual que Tacna sea uno de los lugares de más alta incidencia de viH en el sur peruano, y que Arica tenga el primer lugar en Chile. Tacna deviene, por otra parte, en una ciudad de territoriantes, "habitantes a tiempo parcial" (Muñoz, 2008, p. 27) que solo consumen fragmentos de ciudad; sus zonas centrales no se definen por la fijación, sino por el movimiento y, aun cuando constituyen lugares intensos de la reproducción material de la ciudad —y por consiguiente, lugares efectivos de trabajo para miles de peruanos- se erigen como clásicos "no lugares" para los cientos de miles de visitantes-compradores. Citando a Augé (1992, p. 45), como "palimpsestos donde se reinscribe sin cesar el juego intrincado de la identidad y de la relación". La ciudad, por consiguiente, está obligada a dirigir una buena parte de su inversión pública hacia estos fragmentos urbanos que deben garantizar seguridad, higiene y diversión, en detrimento de la otra Tacna, la que uno encuentra cuando sale de los circuitos "urbanalizados".

Un rasgo de esta relación es la desproporción entre los contactos cotidianos y los que se producen desde la actividad pública formal. Existen espacios bilaterales de contactos entre organismos sociales y políticos de ambas partes -incluyendo los que tienen lugar en un espacio de concertación denominado Comité de Integración y Desarrollo Fronterizo (Álvarez, 2017) — pero toda esta gama de contactos formales son sumamente discretos en comparación con la magnitud de los intercambios cotidianos, donde se despliegan solidaridades y cooperaciones pero mediadas por relaciones de mercado.

Desde aquí se establece un tipo de relación que nos permite acercarnos críticamente a dos cuestiones: la primera, a la función de la frontera; la segunda, a la propuesta de las "identidades mestizas" que en algún momento nos adelantara Tarrius (2000) mencionado al inicio.

En el primer sentido, la idea tradicional de la frontera como eje contradictorio de contacto-separación sigue vigente, pero este contrapunteo pasa a un segundo plano en un contexto en que las fronteras devienen en recursos específicos de la acumulación. Los relacionamientos fronterizos -involucren personas, capitales, mercancías o informaciones- no son simplemente un tránsito entre los polos de un binomio y un recolocamiento de "ellos y nosotros", tal y como lo explicaron desde sus obras seminales autores como Donnan y Wilson (1990) y Martínez (1994). Dejar la observación en este plano es reducir el proceso a su apariencia fenoménica. Es así porque en las RTF - y en los cut que las vertebran- las escalas de la propia existencia se mezclan y confunden, aun cuando los funcionarios del control fronterizo traten de recordarnos que existe una línea que defiende al cuerpo nacional de amagos anómicos, que ayer fueron los soldados extranjeros y hoy es una panoplia difuminada de males "globales" 
que incluyen contrabando, drogas, terrorismo, incorrecciones culturales y braceros indocumentados. En las fronteras contemporáneas, la finalidad del control fronterizo es establecer una serie de condiciones de subordinación de los otros, y optimizarlos para su uso como factores de producción, consumo o manipulación simbólica. Se trata, como han sugerido Mezzadra y Neilson (2013, p. 7), de una situación en que "la multiplicación de conexiones y desconexiones territoriales, económicas, sociales y culturales" define la "...capacidad de jerarquización y estratificación de los bordes". Recordando a Foucault (2003), hablamos de un proceso de disciplinarizaciónnormalización, una modalidad de control de los individuos y de los procesos en el tiempo y en el espacio. Es esto lo que convierte a los trabajadores peruanos en ilegales, a las comerciantes hormiga en contrabandistas, a los chilenos en turistas y a la cultura del otro en folclor digerible desde la playa del ocio.

No es aventurado afirmar que, salvo estratos reducidos de chovinistas extremos, tacneños y ariqueños asumen la imprescindibilidad del otro. Un alto directivo de Zofratacna - un empresario de 56 años particularmente agudo en sus juicios- fue explícito en su visión de la relación con Arica: "El chileno mueve a Tacna... la única manera de vender Tacna para los peruanos es venderla con Arica... si Arica crece es más fácil ofertar a Tacna" (Aldo, 2016). Y otro, un comerciante de aceitunas peruano de 42 años que se queja de los embates de los compradores chilenos y aspira a un orden "legal-racional" que posiblemente nunca llegue a ver, lo dijo más rudamente: "Mi gente no acepta a los ariqueños con tanto amor porque tengan primos y tíos allí, sino porque si Arica cierra la frontera una semana, aquí se cagan del hambre" (Raúl, 2017).

Este contexto coloca a unos y otros en una extraña situación en que son reconocidos a partir de sus contribuciones materiales, sean los chilenos "gastadores" y "obsequiosos", o los peruanos "dispuestos para lo que haga falta", al mismo tiempo que la intensidad de los contactos y el peso de la historia los han inducido a asumirse como una suerte de otros íntimos. Ello es visible a través del modo en que las personas entrevistadas han ido asumiendo la presencia de chilenos o de peruanos, según el lugar, y de cómo han ido construyendo otra otredad a partir del rechazo de los inmigrantes de otros lugares.

Un hombre de 72 años, chileno, describía así lo que calificaba:

Estar siendo invadidos por gente de afuera, demasiado (...) por lo que conversa la gente, ahora ya no solamente llega el peruano y el boliviano, está bien, acá llegan colombianos, dominicanos, de todas partes... y ha comenzado a haber más delincuencia, no sé si son ellos los que lo cometen, pero eso está pasando (Anciano I, 2017).

Y otra anciana, nacida en Arica, lo decía directamente:

Yo creo que en relación al resto del país, nosotros estamos tan acostumbrados a vivir con el peruano y el boliviano que son como parte nuestra. Pero nosotros somos una ciudad que hemos convivido la una con la otra y hemos sobrevivido la una con la otra ayudándonos. Lo que si ahora como han llegado muchos colombianos, y no son la mejor gente la que se ha venido para acá (Anciana III, 2017).

Ariqueños que viven en Tacna y tacneños que viven en Arica — propiamente migrantes- ofrecieron sus opiniones sobre los mundos en que trataban de rehacer 
sus vidas. Regularmente los chilenos eran técnicos y profesionales que se implantaban al nivel medio de la sociedad local, mientras que los peruanos resultaban trabajadores manuales que se insertaban en sus estratos inferiores. Lo que les unía era la opinión que la incorporación pasaba inevitablemente por la asimilación, que finalmente no era difícil debido a la familiaridad de la relación y las comparticiones culturales; nada sugería un clima multicultural en que la diferencia fuera asumida como virtud.

El panorama descripto —una región transfronteriza autocontenida, con una extraña relación de intercambio desigual y en medio de enconados litigios fronterizos- pudiera cambiar en un plazo mediano si se desenvolvieran diversos factores concurrentes. Uno de ellos es el clima geopolítico derivado del diferendo que Chile mantiene tanto respecto a Bolivia por una salida al mar de este país - y que involucra directamente a Arica en cuanto puerto histórico de Bolivia-y con Perú por la propiedad de un triángulo rocoso de dos hectáreas en la costa limítrofe. La idea de la Arica trinacional, apuntando a "un régimen especial de soberanía... de soberanía diferenciada”, al decir de Brockmann (2014, p. 92) ha sido justamente una de las propuestas avanzadas más innovadoras que han circulado en este escenario. Y que implicaría cambios de primer orden en la configuración y funcionamiento a mediano plazo de este CUT. En buena medida porque ello supondría avanzar hacia una visión postwestfaliana de la gobernanza territorial, tan distante como concepto instalado en las élites políticas, como necesaria para ir restañando estas cicatrices de la historia.

Finalmente, esta región afronta la probable incidencia de los procesos de territorialización que ocurren al calor de los corredores bioceánicos (сво) que patrocinan los proyectos integracionistas regionales. Estos сво, aún en buena medida en las fases de proyecto y de implementación primaria, no constituyen en lo fundamental lo que su nombre indica, sino sobre todo procesos de colonización y acumulación por desposesión (Harvey, 2003) en función del capital global y en particular de sus núcleos asentados en la zona de Sao Paulo (Bruckmann, 2015; López, 2012). Sus desarrollos supondrían fuertes procesos de reestructuración territorial en la zona que nos compete, que dejaría de ser esa territorialidad cautiva que discutíamos para devenir eslabones de cadenas de valores transnacionales.

Si eso sucediera, muchas cosas cambiarían en el tumultuoso paisaje fronterizo, pero no todo. Tacneños y ariqueños seguirían inventándose sus realidades compartidas y su historia común; seguirían comprando en la frontera, pues como escribieron Donnan y Wilson (1990) en un libro que merece su espacio entre los clásicos, comprar en la frontera es comprar la frontera en sí. Algo que unos y otros están haciendo día a día desde hace un siglo.

\section{Agradecimientos}

Este artículo fue apoyado por el proyecto Conicyt-Fondecyt 1150812 y por la Vicerrectoría de Innovación e Investigaciones de la Universidad Arturo Prat. 


\section{Referencias}

Aduanas de Chile. (2016). Anuario estadístico 2015. Santiago, Chile: Gobierno de Chile, Departamento de Estudios de la Dirección Nacional de Aduanas.

Álvarez, C. (2017). Régimen político transfronterizo actual: El caso de Arica y Tacna. Ponencia presentada en el iv Congreso Latinoamericano y Caribeño de Ciencias Sociales, Flacso de Salamanca, España.

Augé, M. (1992). Los no lugares: Espacios del anonimato. Barcelona, España: Gedisa.

Benedetti, A. (2014). Espacios fronterizos del sur sudamericano. Propuesta de un modelo conceptual para su estudio. Estudios Fronterizos, 15(29), 11-47. Recuperado de http://www.redalyc.org/articulo.oa?id=53031359001

Berganza, I. (2015). La migración peruana en zonas fronterizas. En M. Tapia y A. González (Eds.), Regiones fronterizas: Migración y los desafios para los estados nacionales latinoamericanos (pp.153-176). Santiago, Chile: Ril editores.

Biblioteca del Congreso Nacional de Chile. (2015). Reportes estadísticos comunales 2015.Indicadores demográficos. Recuperado de http://reportescomunales.ben.cl/2015/index. php/Arica\#Poblaci.C3.B3n_total_a.C3.B10_2002_y_proyecci.C3.B3n_de_poblaci. C3.B3n_a.C3.B1o_2015

Brockmann, R. (2014). Bolivia, Chile (Perú) y el mar. En S. Molina (Eds.), Cuadrar el círculo: Las propuestas de solución al conflicto entre Chile y Bolivia (pp.79-94). Santiago, Chile: LOM.

Bruckmann, M. (2015). Recursos naturales y la geopolítica de la integración sudamericana. Buenos Aires, Argentina: Imago Mundi.

Campus, P. y Rosenblit, J. (2011). Aislamiento de la frontera norte de Chile: ¿Problema u oportunidad? En F. Arenas, A. Salazar y A. A. Núñez (Eds.), El aislamiento geográfico: ¿Problema u oportunidad? Experiencias, interpretaciones (pp.59-73). Santiago, Chile: Instituto de Geografía.

Certeau, M. (2008). Andar la ciudad. Bifurcaciones: Revista de Estudios Culturales Urbanos, (7). Recuperado de http://www.bifurcaciones.cl/007/colerese/bifurcaciones_007_reserva.pdf

Dilla, H. (2015). Los complejos urbanos transfronterizos en América Latina. Estudios Fronterizos, 16(31), 15-38.

Donnan, H. y Wilson, T. (1990). Borders: Frontiers of Identity, Nation and State. Londres, Inglaterra: Berrg.

Emmanuel, A. (1972). El intercambio desigual. México: Siglo xxi Editores.

Foucault, M. (2003). Vigilar y castigar. México: Siglo xxı Editores.

Fraser, N. (2006). La justicia social en la era de la política de la identidad. En N. Fraser y A. Honneth (Eds.), ¿¿Redistribución o reconocimiento? (pp. 17-88). Madrid, España: Ediciones Morata.

Frigolett, H. (Junio de 2013). Economías regionales en Chile: desigualdad y heterogeneidad. Programa Cohesión Territorial para el Desarrollo (Documento de trabajo No. 2, Serie Estudios Territoriales). Recuperado de http://www.rimisp.org/wp-content/ files_mf/1372193442DOCUMENTODETRABAJO12FRIGOLETT.pdf 
Gauthier, M. (2015). Los comerciantes hormiga mexicanos de la región de El Paso y Ciudad Juárez. Las tensiones entre la globalización, el aumento de la seguridad y los nuevos regímenes de movilidad. En C. Alba, G. Lins y G. Matthews (Coords.), La globalización desde abajo: La otra economía (pp. 254-282). México: Fondo de Cultura Económica.

Grimson, A. (2000). Fronteras políticas vs. fronteras culturales. En A. Grimson (Ed.), Fronteras, naciones e identidades (pp. 9-34). Buenos Aires, Argentina: Edición Ciccus.

Guizardi, M., Valdebenito, F., López, E y Nazal, E. (2015). Condensaciones en el espacio hiperfronterizo: Apropiaciones migrantes en la frontera norte de Chile. En M. Guizardi (Ed.) Las fronteras del transnacionalismo. Limites y desbordes de la experiencia migrante en el centro y norte de Chile (pp.254-257). Santiago, Chile: Ocho Libros.

Harvey, D. (2003). El nuevo imperialismo. Madrid, España: Akal.

Harvey, D. (2007). Espacios del capital. Hacia una geografía crítica. Madrid, España: Akal.

Herzog, L. A. y Sohn, C. (2014). The Cross-Border Metropolis in a Global Age: A Conceptual Model and Empirical Evidence from the us-Mexico and European Border Regions. Global Society, 1-21. doi: https://10.1080/13600826.2014.948539

Instituto Nacional de Estadística e Informática (INEI). (s.f.). Población del 2000 al 2015. Recuperado de http://proyectos.inei.gob.pe/web/poblacion/

Instituto Nacional de Estadísticas (INE). (2016). Encuesta suplementaria de ingresos 2016. Síntesis de resultados. Región metropolitana. Recuperado de http://www.ine.cl/ docs/default-source/ingresos-y-gastos/esi/ingreso-de-hogares-y-personas/resultados/2016/esi_sintesis_2016_rm.pdf?sfvrsn=4

Jessop, B. (2001). The Political Economy of Scale. En M. Perkmann y N. Sum (Eds.), Globalization, Regionalization and Cross Border Regions (pp. 25-46). Londres, Inglaterra: Palgrave.

Kearney, M. (2003). Fronteras y límites del Estado y el Yo al final del imperio. Alteridades, 13(25), 47-62. Recuperado de www.redalyc.org/articulo.oa?id=74702506

Kearney, M. (2008). La doble misión de las fronteras como clasificadoras y como filtros de valor. En L. Velasco (Ed.), Migración, fronteras e identidades étnicas transnacionales (pp. 79-116). México: Miguel Ángel Porrúa.

Lins, G. (2015). Conclusión. La globalización desde abajo y el sistema mundial no hegemónico: La otra economía mundial. En C. Alba, G. Lins y G. Matthews (Eds.), La globalización desde abajo, (pp. 407-433). México: Fondo de Cultura Económica.

López, R. (2012). Nuevo instrumento de regionalismo sudamericano. Resultados de la Iniciativa para la Integración de la Infraestructura Regional Sudamericana (IIRSA). En R. Bernal-Meza y S. Quintanar (Eds.), Regionalismo y Orden Mundial: Suramérica, Europa, China (pp. 217-223). Buenos Aires, Argentina: Nuevo Hacer, Universidad Nacional del Centro de la Provincia de Buenos Aires.

Martínez, O. J. (1994). Border People: Life and Society in the US-México Borderland. Arizona, Estados Unidos de América: The University of Arizona Press.

Mezzadra, S. y Neilson, B. (2013). Border as a Method, or, the Multiplication of Labor. Estados Unidos de América: Duke University Press.

Morin, E. (2000). Sociología. Madrid, España: Tecnos. 
Muñoz, F. (2008). Urbanalización. Paisajes comunes, lugares globales. Barcelona, España: Editorial Gustavo Gili.

Narváez, M. (15 de febrero de 2018). Chilenos desembolsaron 2400 millones de pesos en Tacna. La Estrella de Arica. Recuperado de http:/ / www.estrellaarica.cl/impresa/2018/02/15/full/cuerpo-principal/10/

Newman, D. (2011). Contemporary Research Agendas in Border Studies: An Overview. En D. Wastl-Walter (Ed.), The Ashgate Research Companion to Border Studies (pp. 33-47). Farnham, Reino Unido: Ashgate Publishing.

Paredes, R. (2010). La pobreza y su dinámica en el sur del Perú (informe final). Recuperado de http://repositorio.minedu.gob.pe/bitstream/handle/123456789/1301/ La \% 20Pobreza \% 20Y\% 20Su \% 20Din \%C3\%A1 mica\%20En \% 20El\%20Sur\%20 Del\%20Per\%C3\%BA.pdf?sequence=1\&isAllowed $=\mathrm{y}$

Peña, C. (27 de agosto de 2009). Vida al limite en la frontera con Perú (I): El incontenible flujo del contrabando hormiga. Recuperado del sitio de internet de CIPER Centro de Investigación Periodística http://ciperchile.cl/2009/08/27/vida-al-limite-en-la-frontera-con-peru-i-el-incontenible-flujo-del-contrabando-hormiga/

Peña, S. (2008). Ciudades y fronteras: Los retos de la planificación transfronteriza. En H. Dilla (Ed.), Ciudades en la frontera (pp. 263-283). Santo Domingo, República Dominicana: Editora Manatí.

Piore, M. (1971). The Dual Labor Market: Theory and Implications. En M. Gordon (Ed.), Problems in Political Economy: An Urban Perspective (pp. 90-94). Massachusetts, Estados Unidos de América: Heath.

Rosiere, S. (2011). Teichopolitics: The Politics of Border Closure. Si Somos Americanos. Revista de Estudios Transfronterizos, XI(1), 151-163.

Sohn, C. (2014). Modelling Cross-Border Integration: The Role of Borders as a Resource. Geopolitics, 19(3), 587-608. doi: https://10.1080/14650045.2014.913029

Tapia, M. (2017). Las fronteras, la movilidad y lo transfronterizo: Reflexiones para un debate. Estudios Fronterizos, 18(37), 61-80. doi: https://10.21670/ref.2017.37. a04

Tarrius, A. (2000). Las circulaciones migratorias: Conveniencia de la noción de "territorio circulatorio". Relaciones, XXI(83).

Universidad de Tarapacá, Red de Desarrollo Económico Territorial y Empleo para América Latina y el Caribe. (Noviembre de 2008). Informe final. Representaciones del poder de las élites regionales. Conflicto y cooperación en la región de Arica y Parinacota. Santiago, Chile: Subsecretaría de Desarrollo Regional y Administrativo.

Urdaneta, A. (2002). Vecindad en la frontera colombo/venezolana: Situaciones de cooperación y conflicto y su incidencia en las relaciones bilaterales. En R. Silié y C. Segura (Eds.), Hacia una nueva visión de las fronteras (pp.105-126). Santo Domingo, República Dominicana: Búho Editorial.

Valero, M. (2006). Ciudad y fronteras. Aldea Mundo, (9), 120-144.

Zona Franca de Iquique (Zofri). (Diciembre de 2016). Boletín estadístico. Iquique, Chile: Autor.

Zona Franca de Tacna (Zofratacna). (2016). Perfil del visitante del día chileno que arriba a Tacna (Informe de investigación) [folleto]. Tacna, Perú: Zofratacna. 


\section{Entrevistas}

Aldo. (26 de junio de 2016). Profesional y alto directivo empresarial peruano residente en Tacna.

Anciano I. (Febrero de 2017). Hombre chileno, jubilado.

Anciana III. (Febrero de 2017). Mujer chilena, dueña de casa.

Entrevistado. (Febrero de 2017). Jubilado que ha llegado a su octava década.

Huris. (13 de octubre de 2016). Profesional joven chilena.

Manuel. (4 de septiembre de 2016). Propietario agrícola chileno, 58 años.

Miguel. (22 marzo de 2017). Chofer chileno residente en Tacna, 33 años.

María. (6 de septiembre de 2016). Comerciante pasera peruana, 38 años.

Ramiro. (16 de septiembre de 2017). Chofer chileno, 46 años.

Raúl. (26 de marzo de 2017). Profesional argentino/peruano, empresario industrial de la aceituna.

Rosa. (7 de septiembre de 2016). Comerciante chilena de ropas usadas, 44 años.

Teresa. (12 de septiembre de 2016). Comerciante chilena, 34 años.

Haroldo Dilla Alfonso

La Habana, Cuba. Historiador y sociólogo con un doctorado en Ciencias del Instituto Politécnico Federal de Lausana, Suiza. Actualmente es Investigador del Instituto de Estudios Internacionales de la Universidad Arturo Prat en Chile. Entre sus publicaciones recientes: el libro Ciudades en el Caribe y los artículos Los complejos urbanos transfronterizos (Estudios Fronterizos, 2015, México), La regionalización precaria en la frontera dominico-haitiana ( $S$ i somos americanos, 2016, Chile) y La Habana y sus fronteras (Historia 396, 2018, Chile).

Camila Álvarez Torres

Iquique, Chile. Licenciada en Historia con mención en Ciencia Política, Pontificia Universidad Católica de Valparaíso, Chile (2011) y Magíster en Ciencias Políticas, Flacso, Ecuador (2015). Actualmente es investigadora asociada del Instituto de Estudios Internacionales de la Universidad Arturo Prat. Entre sus publicaciones más recientes: (2017). Repertorios de acción colectiva en el conflicto portuario chileno: el caso de una federación portuaria en el norte de Chile. En F. Queiroz y C. Diéguez (Eds.), As Metamorfoses do Trabalho Portuário: Mudanças em Contextos de Modernização. Sao Paulo, Brasil (en impresión). 